\title{
STUDY ON EVALUATION OF HUMAN DAMAGE FROM TSUNAMI CONSIDERED CONGESTION OF EVACUEE
}

\author{
Ken-ichi Fujita ${ }^{1}$ and Harumi Yashiro ${ }^{2}$ \\ ${ }^{1}$ Faculty of Engineering, Nagasaki Institute of Applied Science, Japan \\ ${ }^{2}$ School of Systems Engineering, National Defense Academy of Japan, Japan \\ *Corresponding Author, Received: 15 Oct. 2021, Revised: 6 Nov. 2021, Accepted: 12 Nov. 2021
}

\begin{abstract}
In evacuation behavior from the tsunami, street-blockage caused by building damaged by earthquake increase the number of human damage because evacuees walking speed is decreased. To research where the congestion tends to occur in evacuation, the utility of an area-wide mesh such as GIS is considered to be one of the effective methods. In this study, the stochastic evaluation method of human damage in evacuation from tsunami using area-wide mesh proposed by the authors is extended to the method which can be considered both the congestion of evacuee. The congestion is assumed to have occurred from the street blockage caused by the building damaged by the earthquake. The congestion degree is defined by the number of people per sidewalk area in each mesh. Decrement of walking speed in evacuation is expressed by the congestion degree. Moreover, using the proposed method, the variations of the number of the human damage in evacuating from the tsunami by the difference of the evacuation awareness and the congestion by the streetblockage caused by the building damage are discussed.
\end{abstract}

Keywords: Tsunami Evacuation, Human damage probability, Congestion, Street-blockage, Area-wide mesh

\section{INTRODUCTION}

The damage estimation for a large-scale natural disaster caused by an earthquake or tsunami which may occur in the future has been carried out in Japan. In many municipalities, to reduce the damage caused by a natural disaster, disaster prevention and evacuation plans have been planned by using the estimation results. The evaluation of the human damage in the damage estimation is one of the important items. The human damage from the tsunami has been usually evaluated for evacuation behavior from the tsunami. However, in many studies and damage estimations on human damage, the effects of building damage, liquefaction of the ground, and street blockage caused by the largescale earthquake have not been considered. The evaluation result of the human damage considering the street-blockage by building damage by largescale earthquake become large because walking speed of evacuee decrease due to obstacles such as rubbles and collapsed objects on evacuation route caused by the earthquake.

As one of an impact to increase the human damage in evacuation from the tsunami, streetblockage caused by building damage can be considered. In the previous study, the evaluation of the human damage in evacuation from tsunami considering the impact on the street-blockage can be divided into the following two methods. One is the numerical method such as the multi-agent model [1], [2], the other is the method using the area-wide mesh. The authors have proposed a stochastic evaluation method of human damage using the areawide mesh [3], [4]. Variances of walking speed and tsunami inundation speed have been considered in the studies. The walking speed of evacuees has been assumed to be decreased proportionally to sidewalk width. However, consideration of decrease of the walking speed by congestion of evacuee is left for future work.

This study presents a stochastic evaluation method on the human damage in evacuation from the tsunami, taking account of the congestion of evacuees. The area-wide mesh is used to visually represent the distribution of the human damage in evacuation from the tsunami. The congestion is assumed from the street blockage caused by building damage by large-scale earthquakes. The congestion degree is defined by the number of people per sidewalk area of the evacuation route in each mesh. The decrease of walking speed in evacuation is expressed by the congestion degree. Moreover, the variations of the number of the human damage in evacuating from the tsunami by the difference of the evacuation awareness and the congestion by the street-blockage are discussed using the proposed method.

The originality of this study is in the point of using stochastic evaluation for the human damage in evacuating from tsunami considering variances of the walking speed and the tsunami run-up speed.

\section{OUTLINE OF EVALUATION OF HUMAN DAMAGE AND ASSUMPTIONS}




\subsection{Outline of Human Damage}

The area-wide mesh is used to set up evaluation conditions and to consider evaluation results. Population, number of buildings, road network, and geographical conditions of a target area are introduced of GIS (Geographic Information System) data. For the seismic intensity and the tsunami inundation depth, the average value in the mesh area is adopted.

Evacuation distance from the evacuation mesh to the evacuation facility, including the difference of elevation between mesh, is assumed to be 1.5 times the length of plane distance between the centers of mesh.

The human damage probability is evaluated by using the relation between the evacuation time to the evacuation facility and the tsunami arriving time to the facility after earthquake occurrence. The human damage ratio is evaluated by using the tsunami fragility function represented by the relation between the tsunami inundation depth and the human damage [5].

The street-blockage is occurred by the building damage by large-scale earthquake. The blockage ratio is evaluated by using the fragility function of buildings by the earthquake [6].

The walking speed in evacuation is assumed to be decreased by the congestion of evacuees by the street blockage. The congestion is defined by the number of people per sidewalk area of the

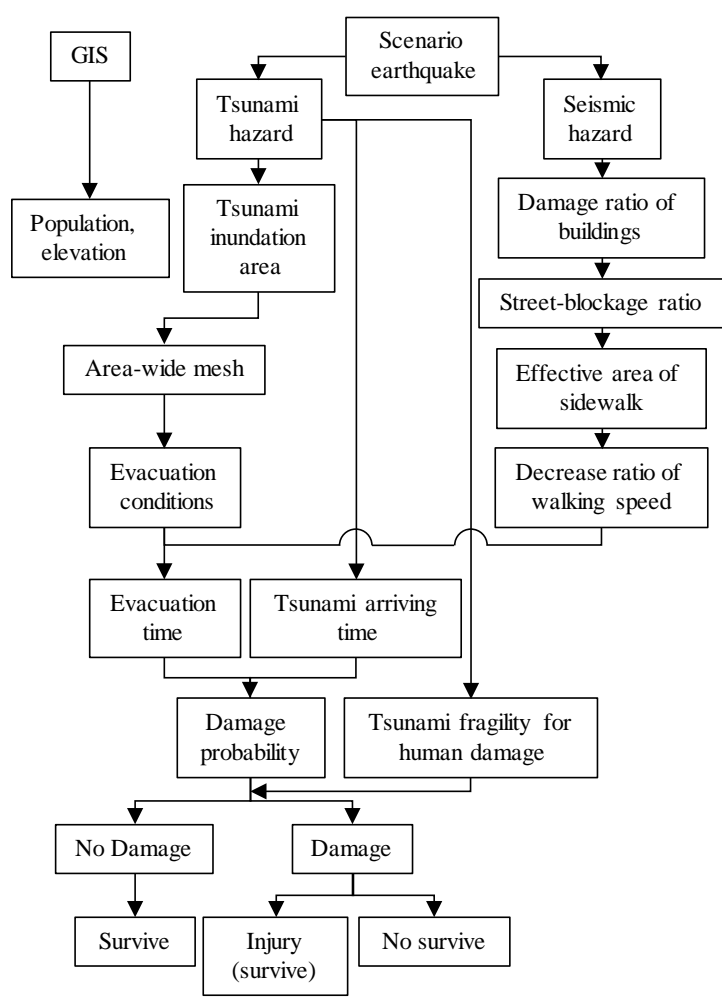

Fig.1 Evaluation flow of human damage evacuation route in each mesh [7]. In addition, to investigate the difference of the human damage by congestion, the occurrence of earthquakes is assumed to be in the daytime.

From the above, the evaluation flow on the human damage in evacuation from a tsunami can be shown in Fig.1.

\subsection{Assumptions in Human Damage Evaluation}

The following assumptions are used in the evaluation.

1) human damage is counted when a person is caught up in a tsunami.

2) The evacuation method is only to walk. Walking is only permitted on the sidewalk.

3) The evacuation direction is not toward to coast.

4) Earthquake occurs in the daytime.

5) The evacuation facility is designated for each evacuation mesh. The damage to evacuation facilities by the earthquake does not occur.

6) Random variables concerning speed and time are assumed to follow a normal distribution.

7) Mean value of walking speed is only decreased by the effect of the congestion. The standard deviation of the walking speed is assumed to be not variable for the congestion.

\section{EVALUATION METHOD OF HUMAN DAMAGE}

\subsection{Human Damage Probability}

The human damage in evacuation from the tsunami is evaluated for each evacuation mesh. The human damage probability is analyzed by using the difference between total time in evacuation behavior after the earthquake occurrence $F_{E}(t)$ and the time from tsunami generating to arrival at evacuation facility $F_{T}(t) . F_{E}(t)$ and $F_{T}(t)$ are assumed to follow normal distribution $N\left(\mu_{E}, \sigma_{E}\right)$ and $N\left(\mu_{T}, \sigma_{T}\right)$, respectively. It should be noted that $\mu_{E}$ and $\sigma_{E}$ are the mean value and standard deviation of $T_{E}$. Also, $\mu_{E}$ and $\sigma_{E}$ are the mean value and standard deviations of $T_{T}$.

The mean values of $T_{E}$ and $T_{T}$ are expressed by the following equations;

$\mu_{E}=t_{S}+t_{W}$

$\mu_{T}=t_{P}+t_{R}$

where $t_{S}$ is the start time of evacuation after the earthquake, $t_{W}$ is the mean value of random variables of the walking time $T_{W}$ obtained by the walking speed and the distance from the start point of evacuation to the evacuation facility, $t_{P}$ is the tsunami propagation time from the epicenter to the 


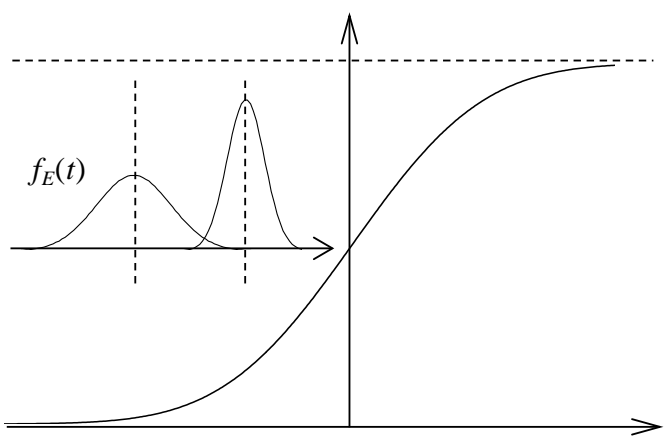

Fig.2 Human survival probability curve

coast, and $t_{R}$ is the mean value of random variables of the tsunami run-up time $T_{R}$ obtained by the runup speed and the distance from the coast to the evacuation facility.

The mean values and the standard deviations of $t_{W}$ and $t_{R}$ in this study have to be evaluated as the inverse function because the walking speed in evacuation $V_{W E}$ and the tsunami ran-up speed $V_{T}$ defined as normal distributions are used. The mean value $\mu_{1 / X}$ and the standard deviation $\sigma_{1 / X}$ of an inverse function of a positive normal variable $X$ with mean value $\mu_{X}$ and standard deviation $\sigma_{X}$ are given by the following equations [8];

$$
\begin{aligned}
& \mu_{1 / X}=\left\{1+\left(\frac{\sigma_{X}}{\mu_{X}}\right)^{2}\right\} \mu_{X} \\
& \sigma_{1 / X}=\frac{\sigma_{X}}{\mu_{X}^{2}} \sqrt{\left\{1-\left(\frac{\sigma_{X}}{\mu_{X}}\right)^{2}\right\}}
\end{aligned}
$$

The mean value and the standard deviation of $T_{W}$ and $T_{R}$ can be evaluated by using Eq. (3) and Eq. (4), respectively.

The human damage probability $P_{D}$ in evacuation can be provided by the following equation.

$$
P_{D}=1-\Phi\left(\frac{\mu_{M}}{\sigma_{M}}\right)
$$

where, $\Phi$ is the standard normal distribution function with $N(0,1), \mu_{M}$ and $\sigma_{M}$ are given by the following equations;

$$
\begin{gathered}
\mu_{M}=\mu_{T}-\mu_{E} \\
\sigma_{M}=\sqrt{\sigma_{T}^{2}+\sigma_{E}^{2}}
\end{gathered}
$$

The human survival probability curve and the probability density function of $f_{E}(t)$ and $f_{T}(t)$ of

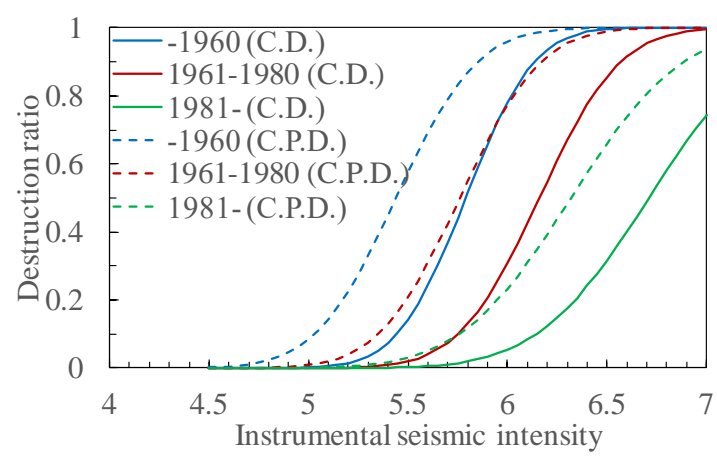

(a) Wooden structure

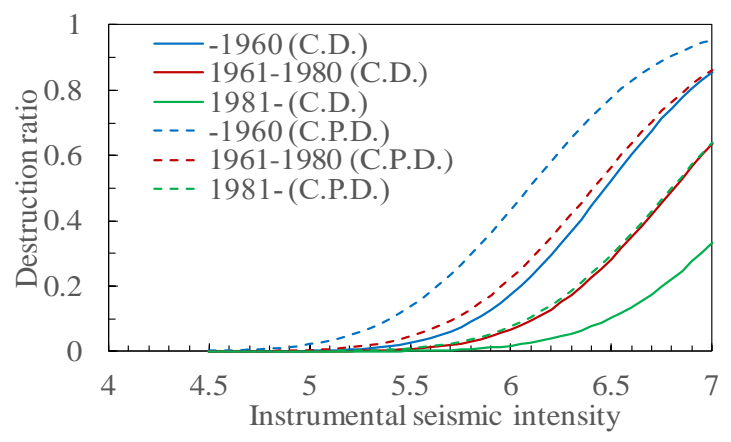

(b) Non-wooden structure

Fig.3 Fragility curve for buildings

probability functions $F_{E}(t)$ and $F_{T}(t)$ are shown in Fig.2.

In addition, the survival probability $P_{S}$ can be expressed by using $P_{D}$ as follows;

$$
P_{S}=1-P_{D}=\Phi\left(\frac{\mu_{M}}{\sigma_{M}}\right)
$$

\subsection{Decrease Ratio of Walking Speed by Congestion}

A decrease in the walking speed is assumed to be occurred by the congestion of the evacuee by the street blockage. The decrease of the walking speed is evaluated for each evacuation mesh. The streetblockage is occurred by the building damage by large-scale earthquake.

Fragility curves of buildings for seismic motion shown in Fig.3 [7] are used for the evaluation of the street blockage. In Fig.3, C.D. is destroyed, C.P.D. is completely and partially destroyed. The fragility is evaluated for each structural type, construction year, and destruction type.

The street-blockage ratio is evaluated for each mesh using the destruction ratio of buildings obtained by using the fragility curve. Evaluation equation for the street-blockage ratio $R_{d}$ is given as follows [7]; 


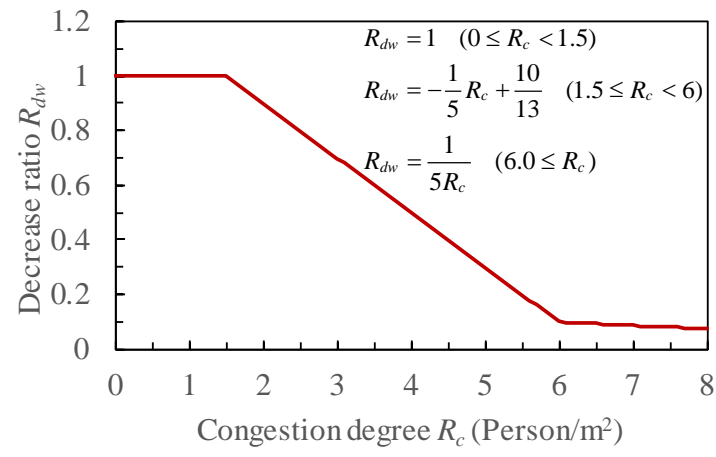

Fig.4 Decrease ratio of walking speed

$$
R_{d}=\left\{\begin{array}{cc}
1.28 D_{d r} & \left(W_{S}<3 m\right) \\
0.604 D_{d r} & \left(3 m \leq W_{S}<5.5 m\right) \\
0.194 D_{d r} & \left(5.5 m \leq W_{S}<13 m\right)
\end{array}\right.
$$

where $W_{S}$ is the road width and $D_{d r}$ is the destruction ratio given by the following equation [7];

$$
D_{d r}=D_{c r}+\frac{D_{p r}}{2}
$$

where, $D_{c r}$ and $D_{p r}$ are the complete and partial destruction of the building, respectively, which can be evaluated by using fragility. The width of the street-blockage Web can be obtained by multiplying $D_{d r}$ and $W_{s}$.

The decrease ratio $R_{w d}$ of the walking speed by the congestion is evaluated for each mesh by the following procedure.

1) Evaluating the sidewalk area in usual condition $A_{s w}$ by subtracting the roadway area $A_{r}$ and the road shoulder area $A_{r s}$ from the total road area in the mesh.

2) Evaluating the sidewalk width in usual condition $W_{s w}$ by dividing the sidewalk area $A_{s w}$ by the road length $L_{r}$ in the mesh.

3) Evaluating the sidewalk width by the streetblockage $W_{s w b}$ by the difference between $W_{s w}$ and Web.

4) Evaluating the sidewalk area considered the street-blockage $A_{s w b}$ by multiplying $W_{s w b}$ and evacuation route length in mesh $L_{r}$.

5) Evaluating the congestion degree $R_{c}$ by dividing the population in mesh $N_{p}$ by $A_{s w b}$.

6) Obtain the decreased ratio of the walking speed $R_{w d}$ by using $R_{c}$.

7) Evaluating the mean value of walking speed in evacuation $v_{W E}$ by multiplying the mean value of the walking speed in usual condition $v_{W}$ and $R_{w d}$.

The relation between the decrease ratio of the walking speed $R_{w d}$ and the congestion degree $R_{c}$ is given in Fig.4 [7].

\section{EVALUATION CONDITIONS}

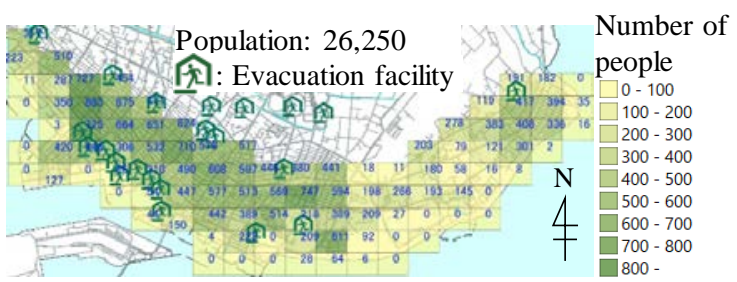

Fig.5 Area-wide mesh and population distribution

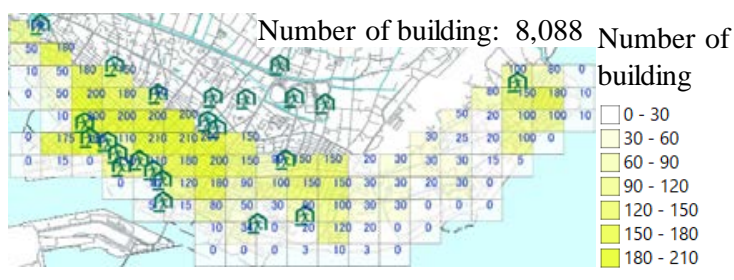

Fig.6 Building distribution

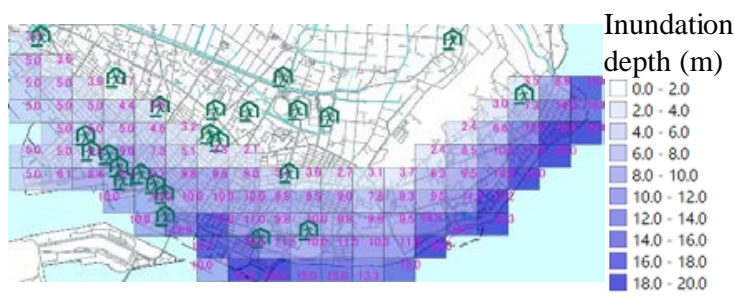

Fig.7 Tsunami inundation depth

\subsection{Area-Wide Mesh, Population, and Number of Buildings}

The area-wide mesh of the target area is shown in Fig.5. The mesh size is $250 \mathrm{~m} \times 250 \mathrm{~m}$. The population in mesh and the location of the evacuation facilities are also shown in the figure. The population is 26,250 persons. The population is large in the west and part of the east.

Building distribution is shown in Fig.6. The number of building in the target area is 8,088; wooden buildings is 813 and non-wooden is 7,275. In addition, geographical conditions, hazard map information of tsunami and seismic intensity, and statistical data of the target area are used to the mesh.

\subsection{Scenario earthquake}

The scenario earthquake used in this study is a Yaeyama islands southern offshore earthquake [9] which moment magnitude $\left(\mathrm{M}_{\mathrm{w}}\right)$ has been estimated to be 9.0. The Seismic intensity on the target area by the earthquake is assumed to be 6-. The intensity of 6- indicates in the range of greater or equal 5.5 and less than 6.0 of measured seismic intensity defined by the Japan Meteorological Agency [10].

\subsection{Tsunami}




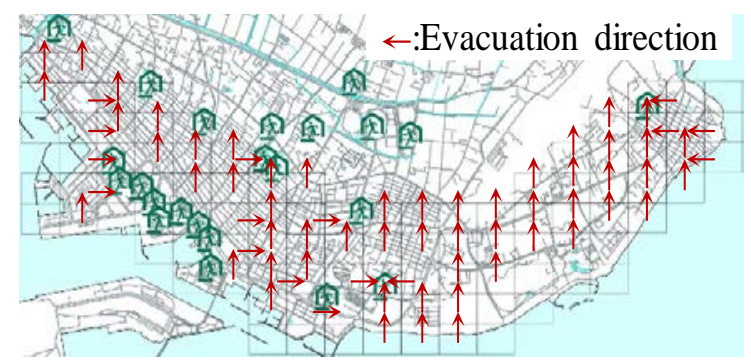

Fig.9 Evacuation route

The tsunami inundation depth of the target area obtained by the damage estimation result on the scenario earthquake is used.

The tsunami inundation depth is shown in Fig.7. In addition, the maximum tsunami height is $22 \mathrm{~m}$ and the arriving time of the tsunami first wave is 16 minutes [9]. The mean value of tsunami run-up speed $v_{T}$ is evaluated by using the following equation [11];

$v_{T}=1.1 \sqrt{g h}$

where $g$ is the gravitational acceleration and the tsunami inundation depth. The standard deviation $\sigma_{T}$ of the tsunami run-up speed is assumed $0.1 v_{T}$ in this study.

\subsection{Evacuation}

Evacuation routes are shown in Fig.9. The red arrow in the figure is the evacuation direction.

The evacuation behavior is divided into four types: evacuation immediately, evacuation after work, urgency evacuation, and no evacuation. The evacuation awareness is categorized into three types; high, normal, and low awareness. Population for this awareness is grouped by combining the four types of evacuation behavior [6]. The population ratio for evacuation awareness is shown in Table 1. The start time of evacuation for several conditions is shown in Table 2.

The mean value $v_{W}$ and the standard deviation $\sigma_{W}$ of walking speeds are used statistical results for middle-aged in the previous study [12]. $v_{W}$ is $1.34 \mathrm{~m} / \mathrm{s}$ and $\sigma_{W}$ is $0.167 \mathrm{~m} / \mathrm{s}$.

\section{EVALUATION RESULTS OF HUMAN DAMAGE}

The human damage in evacuation from tsunami using the proposed method is discussed by the difference of the evacuation awareness and the effect of the congestion by the street-blockage.

\subsection{Evaluation Results without Congestion}

The human damage under the condition neither
Table 1 Population ratio for evacuation awareness

\begin{tabular}{ccccc}
\hline \multirow{2}{*}{$\begin{array}{c}\text { Evacuation } \\
\text { awareness } \\
\text { level }\end{array}$} & $\begin{array}{c}\text { Immediately } \\
\text { (High) }\end{array}$ & $\begin{array}{c}\text { After work } \\
\text { (Low) }\end{array}$ & $\begin{array}{c}\text { Urgency } \\
\text { (Low) }\end{array}$ & $\begin{array}{c}\text { No } \\
\text { evacuation } \\
\text { (Low) }\end{array}$ \\
\hline High & $80 \%$ & $10 \%$ & $5 \%$ & $5 \%$ \\
Normal & $50 \%$ & $25 \%$ & $15 \%$ & $10 \%$ \\
Low & $15 \%$ & $35 \%$ & $30 \%$ & $20 \%$ \\
\hline
\end{tabular}

Table 2 Start time of evacuation

\begin{tabular}{ccc}
\hline Immediately & $\begin{array}{c}\text { After } \\
\text { work }\end{array}$ & Urgency \\
\hline 5 min. & 15 min. & $\begin{array}{c}\text { tsunami arriving } \\
\text { time }\end{array}$ \\
\hline
\end{tabular}

Table 3 Evaluation results of human damage

\begin{tabular}{ccc}
\hline Evacuation & \multicolumn{2}{c}{ Damaged population (persons) } \\
\cline { 2 - 3 } awareness & Without congestion & Congestion \\
\hline level & 7,130 & 9,918 \\
High & 13,501 & 15,245 \\
Normal & 20,941 & 21,465 \\
Low &
\end{tabular}

the congestion nor the street-blockage are discussed. Evaluation results of the human damage distribution for different evacuation awareness are shown in Fig. 9 and the number of the human damage is shown in Table 3 . The number of human damage becomes large with decreasing evacuation awareness. The number of human damage increases in some meshes for a high level of evacuation awareness. The number of the damage increases in the west and part of the east for the low level of awareness.

\subsection{Evaluation Results with Congestion}

Evaluation results of the human damage under the condition with the congestion by the streetblockage are discussed.

\subsubsection{Building Damage}

The destruction ratio of the building is shown in Fig.10. The destruction ratio can be evaluated by using the fragility function shown in Fig.3. The destruction is large in the west and part of the east. The ratios are 0.1 to 0.15 for the mesh with a large number of buildings and 0.05 to 0.1 for the mesh with a small number of buildings. The number of destroyed buildings is 404 and that of partially destroyed is 750 .

\subsubsection{Congestion of evacuee}

The congestion degree for each evacuation mesh by the street blockage caused by the building damage is shown in Fig.11. The congestion tends to 
increase in the evacuation mesh with a large population and to pass the route in the serious damage of the building. The walking speed in evacuation decreases for the applicable mesh.

\subsubsection{Human damage}

Evaluation results of the human damage distribution for different evacuation awareness are shown in Fig.12 and the number of the human damage is also shown in Table 3 . The human damage, considering the congestion, is larger than that of the result without the congestion despite the difference in the evacuation awareness. The human damage for the high awareness is 1.39 times larger than that of the result without the congestion. The normal awareness and the low awareness are 1.13 times and 1.03times larger than those of the results without the congestion. The human damage, considering the congestion in the evacuation, increases despite the difference in the evacuation awareness.

\section{CONCLUSIONS}

A stochastic evaluation method of the human damage in the evacuation from tsunami considering the congestion by the street-blockage caused by the

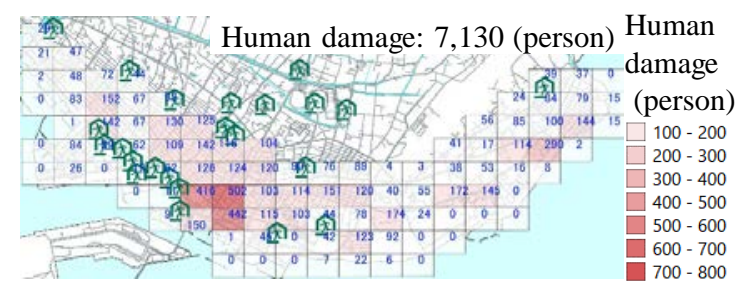

(a) High evacuation awareness

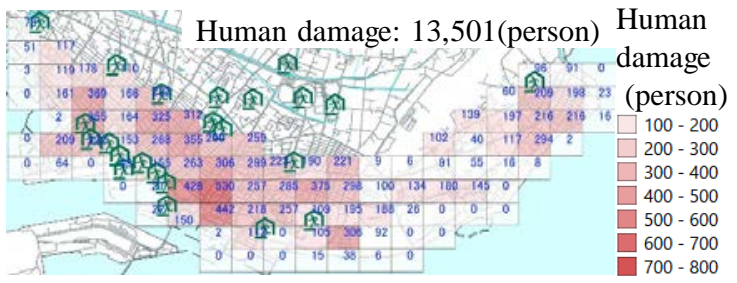

(b) Normal evacuation awareness

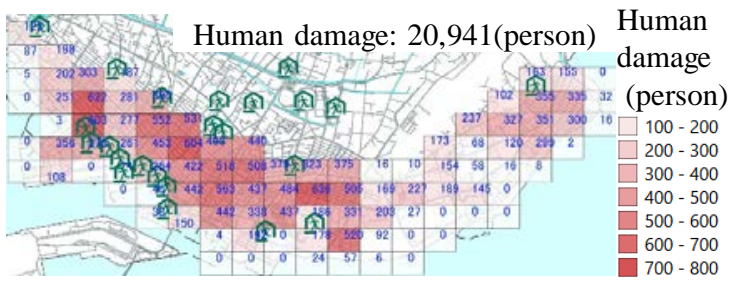

(c) Low evacuation awareness

Fig.9 Human damage distribution in evacuation from tsunami without congestion building collapse was presented. The number of the human damage by the difference of the evacuation awareness and the congestion was discussed.

The following conclusions can be drawn.

1) The human damage considering the congestion increases than that of the result of without the congestion despite the difference of the evacuation awareness.

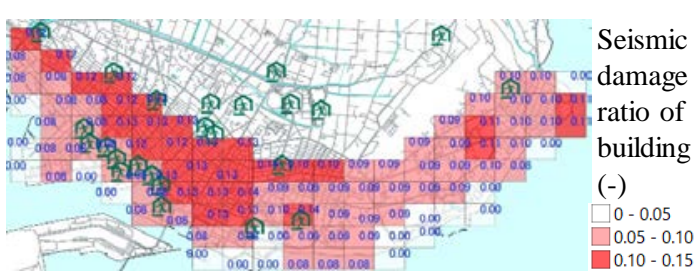

Fig.10 Destruction ratio of building

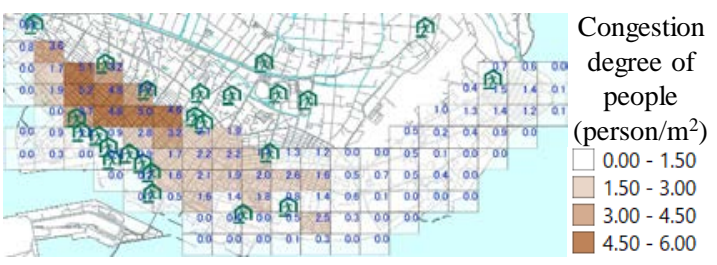

Fig.11 Congestion degree by street-blockage

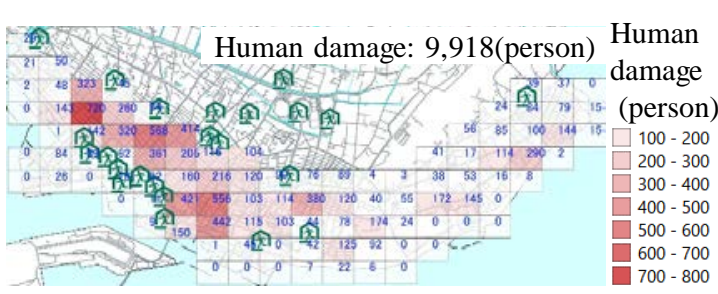

(a) High evacuation awareness

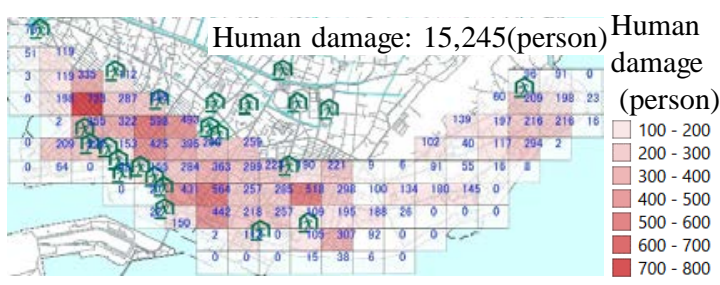

(b) Normal evacuation awareness

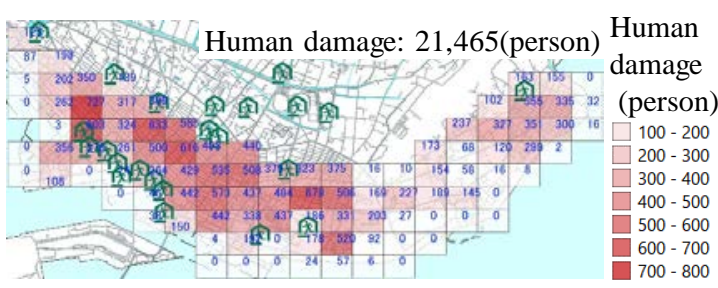

(c) Low evacuation awareness

Fig.12 Human damage distribution in evacuation from the tsunami with congestion 
2) The impact of the congestion is enormous. Even if the evacuation awareness is high, the human damage increases because the walking speed is decreased.

3) To consider the congestion by the streetblockage caused by building collapse is important in the evaluation of the human damage in evacuation from the tsunami.

\section{REFERENCES}

[1] Watanabe Y., Kumagai K., Study of Effects on Tsunami Evacuation Safety of the Mitigation Measures and Research of the Evacuation Building Location Method, Technical Note of National Institute for Land and Infrastructure Management, No.675, 2012. (in Japanese)

[2] Ito E., Kawase H., Matsuyama S., Hatayama M., Tsunami Evacuation Simulation Considering Road Blockade Based on Building Collapse Ratios Evaluated from Predicted Strong Ground Motion, J. of Japan Association for Earthquake Engineering, Vol.15, No.5, 2015, pp.17-30. (in Japanese)

[3] Fujita K., and Yashiro H., A Study on Human Damage in Evacuation from Tsunami Considering Street-Blockades Caused by Destroy of Buildings, International Journal of GEOMATE, Vol. 19, Issue 72, 2020, pp.1-7.

[4] Fujita K., and Yashiro H., Human Damage Estimation in Evacuation from Tsunami Caused by a Common Scenario Trench-Type Earthquake, Proc. of the 30th European Safety and Reliability Conf. and the 15th Probabilistic Safety Assessment and Management Conf.,
2020, pp.508-516.

[5] Koshimura S., Namegawa Y., Yanagisawa H., Fragility Functions for Tsunami Damage Estimation, Journal of Japan Society of Civil Engineers, ser. B, Vol.65, No.4, 2009, pp.320-331. (in Japanese)

[6] Cabinet Office of Japan, Damage Estimation of Nankai Trough Earthquake (1st. Report), 2012. (in Japanese)

[7] Cabinet Office of Japan, Simulation Results on Return Home Action, 2007. (in Japanese)

[8] Nakamura T., On the Moment of Positively Truncated Normal Distribution, J. of Japan Statist. Soc., Vol.10, No.2, 1980, pp.139-134. (in Japanese)

[9] Okinawa Pref., website, Report of Survey on Estimation of Earthquake damage in Okinawa Prefecture in 2013, https://www.pref.okinawa. jp/site/chijiko/bosai/h25jishinhigaisoutei.html (Reference: 2021.5.13)

[10] Japan Meteorological Agency., Commentary on the Japan Meteorological Agency Seismic Intensity Class, https://www.jma.go.jp/jma /kishou/know/shindo/jma-shindo-kaisetsupub.pdf (Reference: 2021.5.13)

[11] Shuto N, Imamura F., Koshimura S., Satake K., Matsutomi H., eds., Encyclopedia of Tsunami, Asakura Publishing Co., Ltd., 2007. (in Japanese)

[12] Matsumoto N., Kiyota S., Ito M., Relationship between the Characteristics of Streetscape and Walking Speed, Journal of Architecture and Planning, Vol.74, No.640, 2009, pp.13711377. (in Japanese)

Copyright (C) Int. J. of GEOMATE All rights reserved, including making copies unless permission is obtained from the copyright proprietors. 